\title{
BILANGAN DOMINASI TOTAL PADA TRIANGULAR SNAKE GRAPH
}

\author{
Murti, Mariatul Kiftiah, Fransiskus Fran
}

\begin{abstract}
INTISARI
Graf $G=(V, E)$ dengan $V$ adalah himpunan titik dan $E$ adalah himpunan sisi yang menghubungkan sepasang titik. Himpunan $D \subseteq V, D$ disebut himpunan dominasi pada graf $G$ jika semua titik yang tidak berada pada himpunan $D$ bertetangga sedikitnya dengan satu titik dari $D$ dan kardinalitas minimum dari $D$ disebut bilangan dominasi $\gamma(G)$. Persekitaran $S$ atau $N(S)$ adalah himpunan semua titik di G yang bertetangga dengan titik-titik di $S$. Himpunan $S \subseteq V$ adalah himpunan dominasi total dalam $G$ jika $N(S)=$ $V$ dan kardinalitas minimum dari himpunan dominasi total dari graf $G$ dilambangkan dengan $\gamma_{t}(G)$. Penelitian ini membahas tentang bilangan dominasi total pada triangular snake graph $\left(T_{n}\right)$, line graph $\left(L\left(T_{n}\right)\right)$ dan splitting graph $\left(S^{\prime}\left(T_{n}\right)\right)$ dari triangular snake graph $\left(T_{n}\right)$. Triangular snake graph $\left(T_{n}\right)$ adalah suatu bentuk graf yang diperoleh dari lintasan graf $P_{n}$ dengan mengganti semua sisi lintasan graf $P_{n}$ dengan segitiga $C_{3}$. Line graph $\left(L\left(T_{n}\right)\right)$ adalah bentuk pemberian titik pada setiap sisi yang bersisian di graf $G$. Sedangkan splitting graph $\left(S^{\prime}\left(T_{n}\right)\right)$ adalah graf yang diperoleh dengan menambahkan titik baru $v^{\prime}$ sesuai dengan titik $v$ dari $G$ sehingga $N(v)=N\left(v^{\prime}\right)$. Hasil dari penelitian diperoleh bilangan dominasi total pada triangular snake graph, line graph dan splitting graph dari triangular snake graph yaitu $\gamma_{t}\left(T_{n}\right)=\left\lfloor\frac{2 n}{3}\right\rfloor$, $\gamma_{t}\left(L\left(T_{n}\right)\right)=\left\lceil\frac{2 n}{3}\right\rceil$ dan $\gamma_{t}\left(S^{\prime}\left(T_{n}\right)\right)=\left\lfloor\frac{2 n}{3}\right\rfloor$.
\end{abstract}

Kata Kunci: persekitaran, line graph, splitting graph

\section{PENDAHULUAN}

Teori graf adalah bagian dari matematika diskrit yang digunakan sebagai alat bantu untuk menggambarkan atau menyatakan suatu persoalan menjadi lebih sederhana dan mudah dipahami. Salah satu materi pada teori graf adalah himpunan dominasi total. Himpunan dominasi total dari graf $G=(V, E)$ merupakan suatu himpunan $S$ dari titik-titik di $G$ yang setiap titik di $G$ bertetangga dengan titik di $S$, dan $G$ tidak memiliki titik terpencil. Himpunan persekitaran di $S$ atau $N(S)$ adalah himpunan semua titik di $G$ yang bertetangga dengan titik-titik di $S$. Himpunan $S \subseteq V(G)$ adalah himpunan dominasi total di $G$ jika setiap titik dalam $V(G)$ bertetangga dengan titik di $S$ sehingga memenuhi $N(S)=V$ [1]. Bilangan dominasi total dari graf $G$ yang dilambangkan dengan $\gamma_{t}(G)$ adalah kardinalitas minimum dari himpunan yang mendominasi total di $G$.

Penerapan himpunan dominasi total yaitu pada konsep jaringan terpusat [1]. Jaringan terpusat yaitu jaringan yang terdiri dari komputer client dan jaringan komputer. Komputer client bertugas sebagai perantara dalam mengakses sumber informasi atau data yang berasal dari jaringan komputer. Dalam hal ini penggolongan himpunan dominasi total pada jaringan terpusat yaitu berdasarkan metode koneksi dalam pemprosesan data yaitu melalui jaringan berkabel (wired network) untuk menghubungkan satu komputer dengan komputer lain diperlukan penghubung berupa kabel jaringan. Kabel jaringan berfungsi dalam mengirim informasi dalam bentuk sinyal listrik antar komputer jaringan. Dengan kata lain bahwa komputer client bertetangga dengan jaringan komputer yang dihubungkan oleh metode koneksi yaitu melalui jaringan berkabel.

Penelitian ini membahas himpunan dominasi total pada triangular snake graph serta line graph dan splitting graph dari triangular snake graph. Triangular snake graph adalah suatu bentuk graf yang diperoleh dari graf lintasan yaitu graf $P_{n}$ dengan mengganti semua sisi graf $P_{n}$ dengan segitiga $C_{3}$ [8]. 
Dari triangular snake graph dapat dibentuk graf baru yaitu line dan splitting. Line graph dari triangular snake graph adalah perubahan sisi menjadi titik pada setiap sisi yang sisinya saling bersisian pada triangular snake graph [9]. Sedangkan splitting graph dari triangular snake graph adalah penambahan titik-titik baru $v^{\prime}$ sesuai dengan titik $v$ dari triangular snake graph sehingga $N(v)=N\left(v^{\prime}\right)[10]$.

\section{TERMINOLOGI DASAR GRAF}

Berikut ini definisi terminologi dasar yang perlu diketahui yaitu sebagai berikut:

Definisi 1 [2] Diberikan graf sederhana $G=(V, E)$. Persekitaran dari titik $v \in V$ dinotasikan dengan $N(v)$ adalah himpunan yang elemen-elemennya bertetangga (adjacent) dengan titik $v$,

$$
N(v)=\{x \in V \mid v x \in E\}
$$

Definisi 2 [3] Diberikan graf sederhana $G=(V, E)$ dan $S \subseteq V$ maka $N(S)=\cup_{v \in S} N(v)$.

Contoh 3 Diberikan sebuah graf $G$ dengan $G=\left(\left\{v_{1}, v_{2}, v_{3}, v_{4}\right\},\left\{e_{1}, e_{2}, e_{3}, e_{4}, e_{5}\right\}\right) . e_{1}=\left(v_{1}, v_{2}\right), e_{2}$ $=\left(v_{2}, v_{4}\right), e_{3}=\left(v_{3}, v_{4}\right), e_{4}=\left(v_{1}, v_{3}\right)$, dan $e_{5}=\left(v_{2}, v_{3}\right)$.

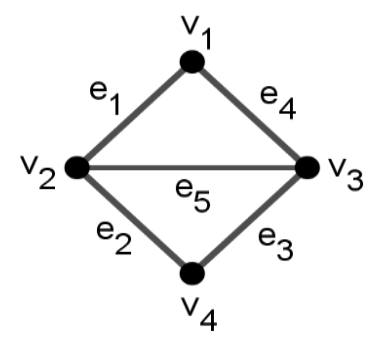

\section{Gambar 1 Graf $G$ dengan 4 titik}

Pada Gambar 1 , titik $v_{1}$ bertetangga dengan titik $v_{2}$ dan titik $v_{3}$, tetapi titik $v_{1}$ tidak bertetangga dengan titik $v_{4}$. Sisi $e_{1}$ bersisian dengan titik $v_{1}$ dan titik $v_{3}$, sisi $e_{2}$ bersisian dengan titik $v_{2}$ dan titik $v_{4}$, tetapi sisi $e_{1}$ tidak bersisian dengan titik $v_{4}$. Persekitaran masing-masing titik di $G$ dengan banyaknya titik $V=\left\{v_{1}, v_{2}, v_{3}, v_{4}\right\}$ adalah $N\left(v_{1}\right)=\left\{v_{2}, v_{3}\right\}, N\left(v_{2}\right)=\left\{v_{1}, v_{3}, v_{4}\right\}, \quad N\left(v_{3}\right)=$ $\left\{v_{1}, v_{2}, v_{4}\right\}, N\left(v_{4}\right)=\left\{v_{2}, v_{3}\right\}$. Di ketahui $S=\left\{v_{2}, v_{3}\right\}$ maka himpunan persekitaran $N(S)=N\left(v_{2}\right) \cup$ $N\left(v_{3}\right)=\left\{v_{1}, v_{3}, v_{4}\right\} \cup\left\{v_{1}, v_{2}, v_{4}\right\}=\left\{v_{1}, v_{2}, v_{3}, v_{4}\right\}$. Himpunan persekitaran di $S$ adalah himpunan semua titik di $G$ bertetangga dengan titik-titik di $S$ yaitu $\left\{v_{1}, v_{2}, v_{3}, v_{4}\right\}$.

Definisi 4 [4] Titik terpencil ialah titik yang tidak mempunyai sisi yang bersisian dengannya, atau dapat juga dinyatakan bahwa titik terpencil adalah titik yang tidak memiliki satupun tetangga dengan titik-titik lainnya.

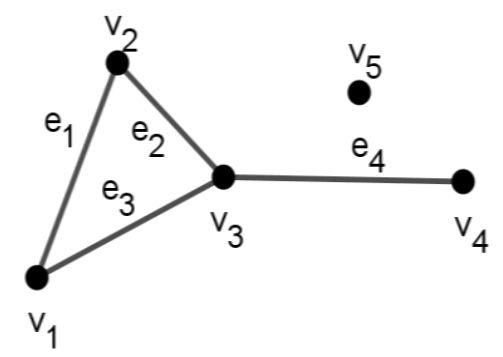

Gambar 2 Graf $G$ dengan 5 titik

Pada Gambar 2 titik terpencil adalah pada titik $v_{5}$ karena tidak ada satu pun sisi yang bersisian dengan titik tersebut.

\section{BILANGAN DOMINASI TOTAL}

Salah satu topik dari teori graf adalah himpunan dominasi. Secara historis, masalah dominasi mulai dipelajari dari tahun 1950 oleh Hedetniemi dan Laskar [5]. 
Definisi 5 [5] Diketahui graf $G=(V, E)$. Misalkan D merupakan subset dari $V$. Jika setiap titik dari $V-D$ saling bertetangga sedikitnya dengan satu titik dari $D$, maka $D$ dikatakan himpunan dominasi pada graf $G$.

Definisi 6 [6] Bilangan dominasi dinotasikan $\gamma(G)$ adalah kardinalitas minimum dari himpunan dominasi.

Contoh 7 Diberikan suatu graf path dengan himpunan titiknya $V=\left\{v_{1}, v_{2}, v_{3}, v_{4}\right\}$ dan himpunan sisinya $E=\left\{e_{1}, e_{2}, e_{3}\right\}$ dengan titik warna hijau adalah titik pada himpunan dominasi total diperlihatkan pada Gambar 3 seperti berikut.

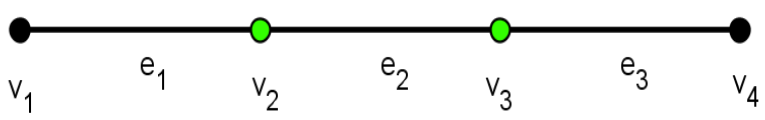

Gambar 3 Graf $P_{4}$

Pada Gambar 3 diketahui $V=\left\{v_{1}, v_{2}, v_{3}, v_{4}\right\}$. Terdapat beberapa kemungkinan himpunan dominasi pada graf $G$ untuk menentukan bilangan dominasi pada graf $G$.

1. Himpunan dominasi $D_{1}=\left\{v_{1}, v_{3}\right\}$. Titik dari $V-D_{1}=\left\{v_{2}, v_{4}\right\}$ saling bertetangga dengan titik dari $D$. Titik $v_{2}$ bertetangga dengan titik $\left\{v_{1}, v_{3}\right\}$, titik $v_{4}$ bertetangga dengan titik $v_{3}$. Jadi $D=\left\{v_{1}, v_{4}\right\}$ merupakan himpunan dominasi dengan kardinalitas 2 .

2. Himpunan dominasi $D_{2}=\left\{v_{2}, v_{3}\right\}$. Titik dari $V-D_{2}=\left\{v_{1}, v_{4}\right\}$ saling bertetangga dengan titik dari $D$. Titik $v_{1}$ bertetangga dengan titik $v_{2}$, titik $v_{4}$ bertetangga dengan titik $v_{3}$. Jadi $D=\left\{v_{2}, v_{3}\right\}$ merupakan himpunan dominasi dengan kardinalitas 2.

Berdasarkan 1 dan 2 pada graf $P_{4}$ bilangan dominasi adalah $\gamma\left(P_{4}\right)=2$.

Salah satu pengembangan bilangan dominasi adalah bilangan dominasi total yang didefinisikan sebagai berikut.

Definisi 8 [1] Diberikan graf $G=(V, E)$ dengan tidak ada titik terpencil dan himpunan $S \subseteq \mathrm{V}$ dengan $S \neq \emptyset$. Himpunan $S$ disebut himpunan dominasi total dalam $G$ jika setiap titik $v \in V$ bertetangga dengan elemen $S$ sehingga memenuhi $N(S)=V$.

Berdasarkan Gambar 3 himpunan dominasi totalnya yaitu $\left\{v_{2}, v_{3}\right\}$. Hal tersebut karena, untuk $S=$ $\left\{v_{2}, v_{3}\right\}$

$$
\begin{aligned}
N(S) & =N\left(v_{2}\right) \cup N\left(v_{3}\right) \\
& =\left\{v_{1}, v_{3}\right\} \cup\left\{v_{2}, v_{4}\right\} \\
& =\left\{v_{1}, v_{2}, v_{3}, v_{4}\right\} \\
& =V
\end{aligned}
$$

Berdasarkan Gambar 3, $v_{2}$ mendominasi $v_{1}$ dan $v_{3}$ sedangkan $v_{3}$ mendominasi $v_{2}$ dan $v_{4}$ yang berarti setiap titik $v_{i} \in V\left(P_{4}\right)$ bertetangga dengan elemen di $\left\{v_{2}, v_{3}\right\}$ maka diperoleh $\gamma_{t}\left(P_{4}\right)=2$.

Diketahui bahwa dari Contoh 7 dari Gambar 3 untuk bilangan dominasi dari graf $P_{4}$ yang dilambangkan dengan $\gamma\left(P_{4}\right)$ adalah kardinalitas minimum dari himpunan dominasi di $P_{4}$ yaitu $\gamma\left(P_{4}\right)=2$, sedangkan bilangan dominasi total dari graf $P_{4}$ yang dilambangkan dengan $\gamma_{t}\left(P_{4}\right)$ adalah kardinalitas minimum dari himpunan yang mendominasi total di $P_{4}$ yaitu $\gamma_{t}\left(P_{4}\right)=2$. Hal ini berakibat bahwa $\gamma(G) \leq \gamma_{t}(G)[7]$.

\section{Bilangan Dominasi Total pada Triangular Snake Graph}

Definisi 9 [8] Triangular snake graph $T_{n}$ diperoleh dari graf lintasan $P_{n}$ dengan mengganti setiap sisi lintasan dengan segitiga $C_{3}$.

Bentuk Triangular snake graph dapat dilihat pada Gambar 4 sebagai berikut. 


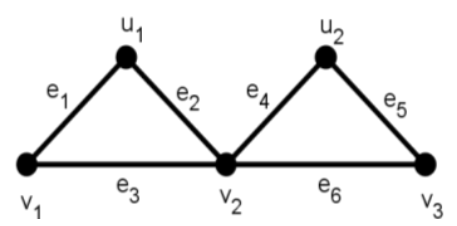

Gambar 4 Graf $T_{3}$

Triangular snake graph dengan jumlah titik berbeda memiliki pola bilangan dominasi total pada Triangular snake graph, sehingga diperoleh proposisi berikut :

Proposisi 10 Untuk Triangular snake graph $T_{n}$ maka $\gamma_{t}\left(T_{n}\right)=\left\lfloor\frac{2 n}{3}\right\rfloor$ untuk $n \geq 3$.

Bukti : Diberikan Triangular snake graph dengan $2 n-1$ titik untuk $n \geq 3$ dan himpunan titik $V\left(T_{n}\right)=\left\{v_{1}, v_{2}, \ldots, v_{n}, u_{1}, u_{2}, \ldots, u_{n-1}\right\}$. Misalkan diambil sebarang $v_{i} \in V\left(T_{n}\right)$ dengan $i \in$ $\{2, \ldots, n-1\}$ sehingga $v_{i}$ mendominasi titik $\left\{v_{i-1}, v_{i+1}, u_{i-1}, u_{i}\right\}$. Akibatnya, setiap titik $v_{i}$ mendominasi 4 titik disekitarnya, untuk titik $v_{1}$ dan $v_{n}$ hanya mendominasi 2 titik. Oleh karena itu dapat dipilih salah satu himpunan dominasi total pada graf $T_{n}$ yaitu

1. $\left\{v_{2}, v_{3}, v_{5}, v_{6}, \ldots, v_{3\left[\frac{n}{3}\right\rfloor-1}, v_{3\left[\frac{n}{3}\right]}\right\}$ untuk $n=3 k, k \in \mathbb{N}$

$$
\begin{aligned}
N(S)= & \left.N\left(v_{2}\right) \cup N\left(v_{3}\right) \cup \ldots \cup N\left(v_{3} \mid \frac{n}{3}\right\rfloor-1\right) \cup N\left(v_{3\left\lfloor\frac{n}{3}\right\rfloor}\right) . \\
= & \left\{v_{1}, v_{3}, u_{1}, u_{2}\right\} \cup\left\{v_{2}, v_{4}, u_{2}, u_{3}\right\} \cup \ldots \cup\left\{v_{\left(3\left\lfloor\frac{n}{3} \mid-1\right)-1\right.}, v_{\left(3\left\lfloor\frac{n}{3}\right\rfloor-1\right)+1}, u_{\left(3\left\lfloor\frac{n}{3}\right\rfloor-1\right)-1}, u_{3\left\lfloor\frac{n}{3}\right\rfloor-1}\right\} \\
& \cup\left\{v_{\left(3\left\lfloor\frac{n}{3} \mid\right)-1\right.}, u_{\left(3\left\lfloor\frac{n}{3} \mid\right)-1\right.}\right\}=V .
\end{aligned}
$$

2. $\left\{v_{2}, v_{3}, v_{5}, v_{6}, \ldots, v_{3\left[\frac{n}{3}\right]-1}, v_{3}\left[\frac{n}{3}\right]\right\}$ untuk $n=3 k+1, k \in \mathbb{N}$

$$
\begin{aligned}
& \left.N(S)=N\left(v_{2}\right) \cup N\left(v_{3}\right) \cup \ldots \cup N\left(v_{\left.3 \mid \frac{n}{3}\right\rfloor-1}\right) \cup N\left(v_{3} \mid \frac{n}{3}\right\rfloor\right) . \\
& \left.=\left\{v_{1}, v_{3}, u_{1}, u_{2}\right\} \cup\left\{v_{2}, v_{4}, u_{2}, u_{3}\right\} \cup \ldots \cup\left\{v_{\left(3\left|\frac{n}{3}\right|-1\right)-1}, v_{\left(3\left|\frac{n}{3}\right|-1\right)+1}, u_{\left(3\left\lfloor\frac{n}{3}\right\rfloor-1\right)-1}, u_{3} \mid \frac{n}{3}\right\rfloor-1\right\} \\
& \cup\left\{v_{\left(3\left(\frac{n}{3} \mid\right)-1\right.}, v_{\left.\left(3 \mid \frac{n}{3}\right]\right)+1}, u_{\left(3\left[\frac{n}{3} \mid\right)-1\right.}, u_{3\left(\frac{n}{3}\right]}\right\}=V \text {. }
\end{aligned}
$$

3. $\left.\left\{v_{2}, v_{3}, v_{5}, v_{6}, v_{8}, v_{9} \ldots, v_{3}\left|\frac{n}{3}\right|-1, v_{3} \mid \frac{n}{3}\right\}\right\}\left\{v_{n-1}\right\}$ untuk $n=3 k+2, k \in \mathbb{N}$

$$
\begin{aligned}
& N(S)=N\left(v_{2}\right) \cup N\left(v_{3}\right) \cup \ldots \cup N\left(v_{3\left|\frac{n}{3}\right|-1}\right) \cup N\left(v_{3\left|\frac{n}{3}\right|}\right) \cup N\left(v_{n-1}\right) . \\
& =\left\{v_{1}, v_{3}, u_{1}, u_{2}\right\} \cup\left\{v_{2}, v_{4}, u_{2}, u_{3}\right\} \cup \ldots \cup\left\{v_{\left(3\left\lfloor\frac{n}{3}\right\rfloor-1\right)-1}, v_{\left.\left(3 \mid \frac{n}{3}\right\rfloor-1\right)+1}, u_{\left(3\left\lfloor\frac{n}{3} \mid-1\right)-1\right.}, u_{\left.3 \mid \frac{n}{3}\right\rfloor-1}\right\} \\
& \cup\left\{v_{\left.\left(3 \mid \frac{n}{3}\right]\right)-1}, v_{\left(3\left\lfloor\frac{n}{3}\right]\right)+1}, u_{\left.\left(3 \mid \frac{n}{3}\right]\right)-1}, u_{3\left\lfloor\frac{n}{3}\right]}\right\} \cup\left\{v_{(n-1)-1}, v_{(n-1)+1}, u_{(n-1)-1}, u_{n-1}\right\}=V .
\end{aligned}
$$

Sehingga diperoleh bilangan dominasi total $\gamma_{t}\left(T_{n}\right) \leq\left\lfloor\frac{2 n}{3}\right\rfloor$. Selanjutnya akan ditunjukkan bilangan dominasi total minimum pada triangular snake graph $\gamma_{t}\left(T_{n}\right)=\left\lfloor\frac{2 n}{3}\right\rfloor$. Misalkan $\gamma_{t}\left(T_{n}\right)=\left\lfloor\frac{2 n}{3}\right\rfloor-1$ maka terdapat $\left\lfloor\frac{2 n}{3}\right\rfloor-1$ titik yang merupakan kardinalitas minimum dari himpunan dominasi total pada triangular snake graph. Jika terdapat $\left\lfloor\frac{2 n}{3}\right\rfloor-1$ titik pada himpunan dominasi total yang dipilih sembarang maka mengakibatkan paling tidak 1 titik pada graf $T_{n}$ yang tidak terdominasi. Oleh karena itu disimpulkan bahwa bilangan dominasi total pada triangular snake graph yaitu $\gamma_{t}\left(T_{n}\right)=\left\lfloor\frac{2 n}{3}\right\rfloor$. 


\section{Bilangan Dominasi Total pada Line Graph Triangular Snake}

Definisi 11 [9] Misal graf $G$ dengan himpunan titik $V(G)$ dan himpunan sisi $E(G)$. Graf garis (line graph) $L(G)$ adalah graf dengan $V(L(G))=E(G)$ dan titik di $L(G)$ akan bertetangga jika dan hanya jika sisi-sisi yang bersesuaian saling bersisian di $G$.

Bentuk line graph pada triangular snake graph dapat dilihat pada Gambar 5 sebagai berikut.

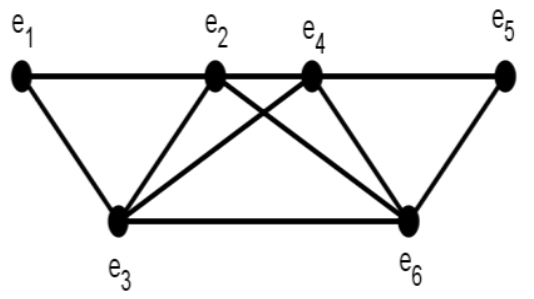

Gambar 5 Graf $L\left(T_{3}\right)$

Line graph pada triangular snake graph dengan jumlah titik berbeda memiliki pola bilangan dominasi total line graph pada triangular snake graph, sehingga diperoleh proposisi berikut :

Proposisi $12 \mathrm{Jika} L\left(T_{n}\right)$ adalah line graph dari triangular snake graph maka $\gamma_{t}\left(L\left(T_{n}\right)\right)=\left\lceil\frac{2 n}{3}\right\rceil$.

Bukti : Diberikan line graph pada triangular snake graph dengan $3 n-3$ untuk $n \geq 3$ dan himpunan titik $V\left(L\left(T_{n}\right)\right)=\left\{e_{1}, e_{2}, e_{3}, \ldots, e_{3 n-3}\right\}$. Diambil sebarang $e_{i} \in V\left(L\left(T_{n}\right)\right)$ dengan $i=3 k, k \in \mathbb{N}$ sehingga $e_{i}$ mendominasi titik pada $\left\{e_{i-3}, e_{i-4}, e_{i-2}, e_{i-1}, e_{i+1,}, e_{i+3}\right\}$ akibatnya setiap titik $e_{i}$ mendominasi 6 titik disekitarnya. Untuk titik $e_{3}$ dan $e_{n}$ mendominasi 4 titik. Oleh karena itu, dapat dipilih salah satu himpunan dominasi total pada graf $L\left(T_{n}\right)$ yaitu

1. $\left\{e_{3}, e_{6}, e_{12}, e_{15}, \ldots, e_{3\left(3\left[\frac{n}{3}\right]-2\right)}, e_{3\left(3\left[\frac{n}{3}\right]-1\right)}\right\}$ untuk $n=3 k, k \in \mathbb{N}$

$$
\begin{aligned}
& N(S)=N\left(e_{3}\right) \cup N\left(e_{6}\right) \cup \ldots \cup N\left(e_{3\left(3\left[\frac{n}{3} \mid-2\right)\right.}\right) \cup N\left(e_{3\left(3\left|\frac{n}{3}\right|-1\right)}\right) \text {. } \\
& =\left\{e_{1}, e_{2}, e_{4}, e_{6}\right\} \cup\left\{e_{2}, e_{3}, e_{4}, e_{5}, e_{7}, e_{9}\right\} \cup \ldots \cup\left\{e_{\left(3\left(3\left[\frac{n}{3}\right]-2\right)\right)-4^{\prime}}, e_{\left(3\left(3\left[\frac{n}{3}\right]-2\right)\right)-3^{\prime}} e_{\left(3\left(3\left[\frac{n}{3}\right]-2\right)\right)-2^{\prime}}\right. \\
& e_{\left(3\left(3\left[\frac{n}{3}\right]-2\right)\right)-1^{\prime}}, e\left(3\left(3\left[\frac{n}{3} \mid-2\right)\right)+1^{\prime}, e\left(3\left(3\left[\frac{n}{3}\right]-2\right)\right)+3\right\} \cup\left\{e_{\left(3\left(3\left[\frac{n}{3}\right]-1\right)\right)-4^{\prime}} e_{\left(3\left(3\left[\frac{n}{3}\right]-1\right)\right)-3^{\prime}}\right. \\
& e_{\left(3\left(3\left[\frac{n}{3}\right]-1\right)\right)-2, e}\left(3\left(3\left[\frac{n}{3} \mid-1\right)\right)-1\right\}=V \text {. }
\end{aligned}
$$

2. $\left\{e_{3}, e_{6}, e_{12}, e_{15}, \ldots, e_{3\left(3\left(\left[\frac{n}{3}\right]-1\right)-2\right)}, e_{3\left(3\left(\left[\frac{n}{3}\right]-1\right)-1\right)}\right\} \cup\left\{e_{3\left(3\left[\frac{n}{3}\right]-3\right)}\right\}$ untuk $n=3 k+1, k \in \mathbb{N}$

$$
\begin{aligned}
& N(S)=N\left(e_{3}\right) \cup N\left(e_{6}\right) \cup \ldots \cup N\left(e_{3\left(3\left(\left[\frac{n}{3}\right]-1\right)-2\right)}\right) \cup N\left(e_{3\left(3\left(\left[\frac{n}{3}\right]-1\right)-1\right)}\right) \cup N\left(e_{3\left(3\left[\frac{n}{3}\right]-3\right)}\right) \text {. } \\
& =\left\{e_{1}, e_{2}, e_{4}, e_{6}\right\} \cup\left\{e_{2}, e_{3}, e_{4}, e_{5}, e_{7}, e_{9}\right\} \cup \ldots \cup\left\{e_{\left(3\left(3\left(\left[\frac{n}{3}\right]-1\right)-2\right)\right)-4}, e_{\left(3\left(3\left(\left[\frac{n}{3}\right]-1\right)-2\right)\right)-3^{\prime}}\right. \\
& e\left(3\left(3\left(\left[\frac{n}{3}\right]-1\right)-2\right)\right)-2^{\prime}, e\left(3\left(3\left(\left[\frac{n}{3}\right]-1\right)-2\right)\right)-1^{\prime} e\left(3\left(3\left(\left[\frac{n}{3}\right]-1\right)-2\right)\right)+1^{\prime} e\left(3\left(3\left(\left[\frac{n}{3} \mid-1\right)-2\right)\right)+3\right\} U
\end{aligned}
$$

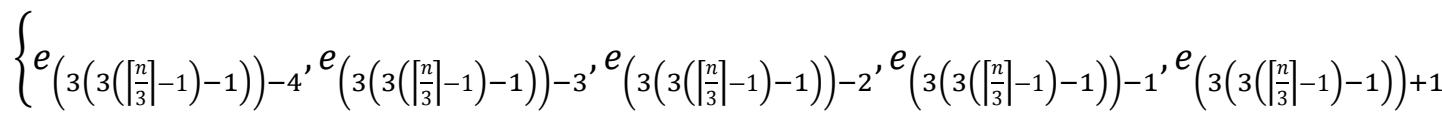

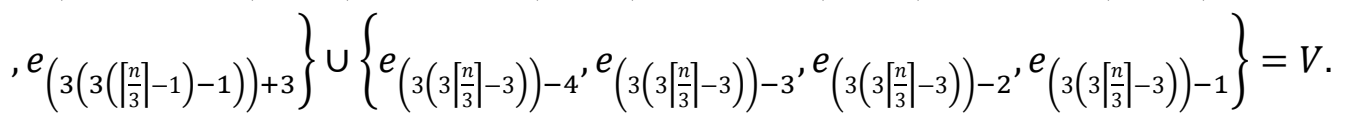


3. $\left\{e_{3}, e_{6}, e_{12}, e_{15}, e_{21}, e_{24}, \cdots, e_{3\left(3\left(\left[\frac{n}{3} \mid-1\right)-2\right)\right.}, e_{3\left(3\left(\left[\frac{n}{3}\right]-1\right)-1\right)}\right\} \cup\left\{e_{3\left(3\left(\frac{n}{3}\right]-3\right)}\right\} \cup\left\{e_{3\left(3\left[\frac{n}{3} \mid-2\right)\right.}\right\}$ untuk $n=3 k+2, k \in \mathbb{N}$

$$
\begin{aligned}
& N(S)=N\left(e_{3}\right) \cup N\left(e_{6}\right) \cup \ldots \cup N\left(e_{\left.3\left(3\left(\frac{n}{3}\right]-1\right)-2\right)}\right) \cup N\left(e_{3\left(3\left(\left[\frac{n}{3}\right]-1\right)-1\right)}\right) \cup N\left(e_{3\left(3\left[\frac{n}{3}\right]-3\right)}\right) \cup \\
& N\left(e_{3\left(3\left[\frac{n}{3}\right]-1\right)}\right) \text {. } \\
& =\left\{e_{1}, e_{2}, e_{4}, e_{6}\right\} \cup\left\{e_{2}, e_{3}, e_{4}, e_{5}, e_{7}, e_{9}\right\} \cup \ldots \cup\left\{e_{\left(3\left(3\left(\left[\frac{n}{3}\right]-1\right)-2\right)\right)-4^{\prime}}\left(3\left(3\left(\left[\frac{n}{3}\right]-1\right)-2\right)\right)-3^{\prime}\right. \\
& \left.e_{\left(3\left(3\left(\left[\frac{n}{3} \mid-1\right)-2\right)\right)-2^{\prime}\right.} e_{\left(3\left(3\left(\left[\frac{n}{3} \mid-1\right)-2\right)\right)-1^{\prime}\right.} e_{\left(3\left(3\left(\left[\frac{n}{3}\right]-1\right)-2\right)\right)+1^{\prime}} e_{\left(3\left(3\left(\left[\frac{n}{3}\right]-1\right)-2\right)\right)+3}\right\} U
\end{aligned}
$$

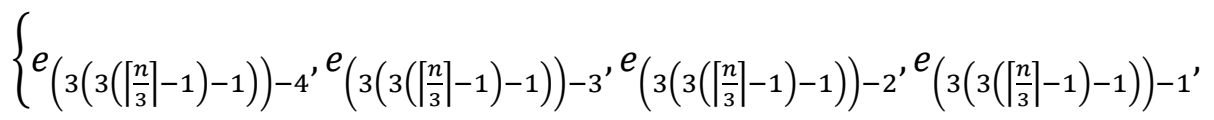

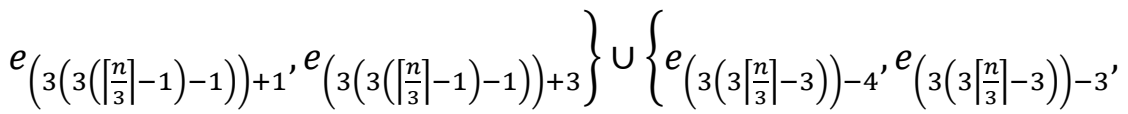

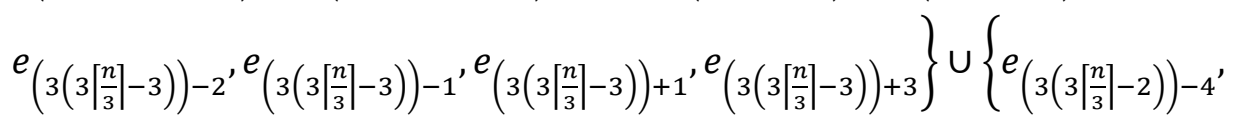

$$
\begin{aligned}
& e\left(3\left(3\left[\frac{n}{3} \mid-2\right)\right)-3^{\prime} e\left(3\left(3\left[\frac{n}{3} \mid-2\right)\right)-2^{\prime} e\left(3\left(3\left[\frac{n}{3} \mid-2\right)\right)-1\right\}=V\right. \text {. }\right.
\end{aligned}
$$

Sehingga diperoleh bilangan dominasi total $\gamma_{t}\left(L\left(T_{n}\right)\right) \leq\left\lceil\frac{2 n}{3}\right\rceil$. Selanjutnya, akan ditunjukkan bilangan dominasi total minimum pada line graph $\gamma_{t}\left(L\left(T_{n}\right)\right)=\left\lceil\frac{2 n}{3}\right\rceil$. Misalkan, $\gamma_{t}\left(L\left(T_{n}\right)\right)=\left\lceil\frac{2 n}{3}\right\rceil-$ 1 maka terdapat $\left\lceil\frac{2 n}{3}\right]-1$ titik yang merupakan kardinalitas minimum dari himpunan dominasi total line graph pada triangular snake graph. Dalam hal ini $\left[\frac{2 n}{3}\right]-1$ titik pada himpunan dominasi total yang dipilih sembarang mengakibatkan ada 1 titik yang tidak terdominasi. Jadi, dapat disimpulkan bilangan dominasi total line graph pada triangular snake graph yaitu $\gamma_{t}\left(L\left(T_{n}\right)\right)=\left\lceil\frac{2 n}{3}\right\rceil$.

\section{Bilangan Dominasi Total pada Splitting Graph Triangular Snake}

Definisi 13 [10] Splitting graph $S^{\prime}(G)$ dari graf $G$ diperoleh dengan menambahkan sebuah titik baru $v^{\prime}$ sesuai dengan titik $v$ dari $G$ sehingga $N(v)=N\left(v^{\prime}\right)$ adalah $N(v)$ dan $N\left(v^{\prime}\right)$ masing-masing adalah persekitaran dari $v$ dan $v^{\prime}$.

Bentuk splitting graph pada triangular snake graph dapat dilihat pada Gambar 6 sebagai berikut.

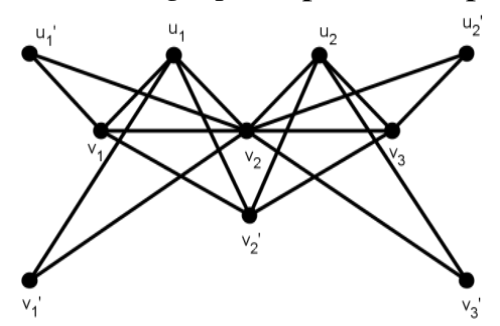

Gambar 6 Graf $S^{\prime}\left(T_{3}\right)$

Splitting graph pada triangular snake graph dengan jumlah titik berbeda memiliki pola bilangan dominasi total splitting graph pada triangular snake graph, sehingga diperoleh proposisi berikut :

Proposisi 14 Jika $S^{\prime}\left(T_{n}\right)$ adalah splitting graph dari triangular snake graph maka $\gamma_{t}\left(S^{\prime}\left(T_{n}\right)\right)=\left\lfloor\frac{2 n}{3}\right\rfloor$. 
Bukti : Diberika splitting graph pada triangular snake graph dengan $4 n-2$ untuk $n \geq 3$ dan himpunan titik $V\left(S^{\prime}\left(T_{n}\right)\right)=\left\{v_{1}, v_{2}, \ldots, v_{n}, v_{1}^{\prime}, v_{2}^{\prime}, \ldots, v_{n}{ }^{\prime}, u_{1}, u_{2}, \ldots, u_{n-1}, u_{1}^{\prime}, u_{2}^{\prime}, \ldots, u_{n-1}^{\prime}\right\}$. Diambil sembarang $v_{i} \in V\left(S^{\prime}\left(T_{n}\right)\right)$ dengan $i \in\{2, \ldots, n-1\}$ sehingga $v_{i}$ mendominasi titik pada $\left\{v_{i-1}, v_{i-1}^{\prime}\right.$, $\left.u_{i-1}, u_{i-1}^{\prime}, u_{i}, u_{i}^{\prime}, v_{i+1}, v_{i+1}^{\prime}\right\}$ akibatnya setiap titik mendominasi 8 titik disekitarnya dan untuk titik $v_{1}$ dan $v_{n}$ hanya mendominasi 4 titik. Oleh karena itu, dapat dipilih salah satu himpunan dominasi total pada splitting graph $S^{\prime}\left(T_{n}\right)$ yaitu

1. $\left\{v_{2}, v_{3}, v_{5}, v_{6}, \ldots, v_{3\left\lfloor\frac{n}{3}\right\rfloor-1}, v_{3\left\lfloor\frac{n}{3}\right\rfloor}\right\}$ untuk $n=3 k, k \in \mathbb{N}$

$$
\begin{aligned}
& N(S)=N\left(v_{2}\right) \cup N\left(v_{3}\right) \cup \ldots \cup N\left(v_{3\left[\frac{n}{3}\right]-1}\right) \cup N\left(v_{3\left[\frac{n}{3} \mid\right.}\right) \text {. } \\
& =\left\{v_{1}, v_{3}, v_{1}^{\prime}, v_{3}^{\prime}, u_{1}, u_{2}, u_{1}^{\prime}, u_{2}^{\prime}\right\} \cup\left\{v_{2}, v_{4}, v_{2}^{\prime}, v_{4}^{\prime}, u_{2}, u_{3}, u_{2}^{\prime}, u_{3}^{\prime}\right\} \cup \ldots \cup\left\{v_{\left(3\left|\frac{n}{3}\right|-1\right)-1^{\prime}}, v_{\left(3\left|\frac{n}{3}\right|-1\right)+1}\right. \\
& \left., v_{\left(3\left\lfloor\frac{n}{3}\right\rfloor-1\right)-1}^{\prime}, v_{\left(3\left\lfloor\frac{n}{3}\right\rfloor-1\right)+1}^{\prime}, u_{\left(3\left\lfloor\frac{n}{3}\right\rfloor-1\right)-1}, u_{3\left\lfloor\frac{n}{3}\right\rfloor-1}, u_{\left(3\left\lfloor\frac{n}{3}\right\rfloor-1\right)-1}^{\prime}, u_{3\left(\frac{n}{3}\right\rfloor-1}^{\prime}\right\} \cup\left\{v_{\left(3\left\lfloor\frac{n}{3}\right]\right)-1^{\prime}}\right. \\
& \left.v_{\left(3\left\lfloor\frac{n}{3} \mid\right)-1\right.}^{\prime}, u_{\left(3\left\lfloor\frac{n}{3}\right]\right)-1}, u_{\left(3\left\lfloor\frac{n}{3} \mid\right)-1\right.}^{\prime}\right\}=V \text {. }
\end{aligned}
$$

2. $\left\{v_{2}, v_{3}, v_{5}, v_{6}, \ldots, v_{3\left\lfloor\frac{n}{3}\right\rfloor-1}, v_{3\left\lfloor\frac{n}{3}\right]}\right\}$ untuk $n=3 k+1, k \in \mathbb{N}$

$$
\begin{aligned}
& N(S)=N\left(v_{2}\right) \cup N\left(v_{3}\right) \cup \ldots \cup N\left(v_{3}\left[\frac{n}{3} \mid-1\right) \cup N\left(v_{3}\left|\frac{n}{3}\right|\right)\right. \text {. } \\
& =\left\{v_{1}, v_{3}, v_{1}^{\prime}, v_{3}^{\prime}, u_{1}, u_{2}, u_{1}^{\prime}, u_{2}^{\prime}\right\} \cup\left\{v_{2}, v_{4}, v_{2}^{\prime}, v_{4}^{\prime}, u_{2}, u_{3}, u_{2}^{\prime}, u_{3}^{\prime}\right\} \cup \ldots \cup\left\{v_{\left(3\left|\frac{n}{3}\right|-1\right)-1}, v_{\left(3\left|\frac{n}{3}\right|-1\right)+1}\right.
\end{aligned}
$$

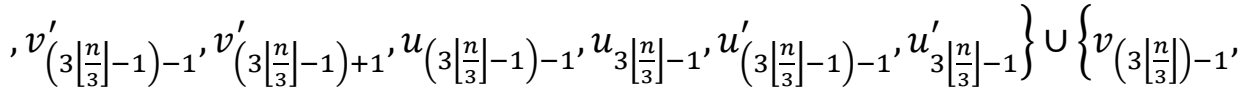

$$
\begin{aligned}
& \left.v_{\left(3\left[\frac{n}{3}\right]\right)+1}, v_{\left(3\left\lfloor\frac{n}{3} \mid\right)-1\right.}^{\prime}, v_{\left(3\left\lfloor\frac{n}{3}\right]\right)+1}^{\prime}, u_{\left(3\left\lfloor\frac{n}{3} \mid\right)-1\right.}, u_{3\left[\frac{n}{3}\right]}, u_{\left.\left(3 \mid \frac{n}{3}\right]\right)-1}^{\prime}, u_{3\left\lfloor\frac{n}{3}\right]}^{\prime}\right\}=V \text {. }
\end{aligned}
$$

3. $\left.\left\{v_{2}, v_{3}, v_{5}, v_{6}, v_{8}, v_{9}, \ldots, v_{3}\left|\frac{n}{3}\right|-1, v_{3} \mid \frac{n}{3}\right\}\right\}\left\{v_{n-1}\right\}$ untuk $n=3 k+2, k \in \mathbb{N}$

$$
\begin{aligned}
& N(S)=N\left(v_{2}\right) \cup N\left(v_{3}\right) \cup \ldots \cup N\left(v_{3\left|\frac{n}{3}\right|-1}\right) \cup N\left(v_{3\left|\frac{n}{3}\right|}\right) \cup N\left(v_{n-1}\right) \text {. } \\
& =\left\{v_{1}, v_{3}, v_{1}^{\prime}, v_{3}^{\prime}, u_{1}, u_{2}, u_{1}^{\prime}, u_{2}^{\prime}\right\} \cup\left\{v_{2}, v_{4}, v_{2}^{\prime}, v_{4}^{\prime}, u_{2}, u_{3}, u_{2}^{\prime}, u_{3}^{\prime}\right\} \cup \ldots \cup\left\{v_{\left(3\left|\frac{n}{3}\right|-1\right)-1^{\prime}}\right. \\
& \left.v_{\left(3\left\lfloor\frac{n}{3}\right\rfloor-1\right)+1}, v_{\left(3\left\lfloor\frac{n}{3}\right\rfloor-1\right)-1}^{\prime}, v_{\left(3\left\lfloor\frac{n}{3}\right\rfloor-1\right)+1}^{\prime}, u_{\left(3\left\lfloor\frac{n}{3}\right\rfloor-1\right)-1}, u_{3\left\lfloor\frac{n}{3}\right\rfloor-1}, u_{\left(3\left\lfloor\frac{n}{3}\right\rfloor-1\right)-1}^{\prime}, u_{3\left\lfloor\frac{n}{3}\right\rfloor-1}^{\prime}\right\} U \\
& \left\{v_{\left(3\left(\frac{n}{3} \mid\right)-1\right.}, v_{\left(3\left\lfloor\frac{n}{3} \mid\right)+1\right.}, v_{\left(3\left\lfloor\frac{n}{3}\right]\right)-1}^{\prime}, v_{\left(3\left[\frac{n}{3}\right]\right)+1}^{\prime}, u_{\left(3\left\lfloor\frac{n}{3} \mid\right)-1\right.}, v_{3\left\lfloor\frac{n}{3}\right]}, u_{\left(3\left\lfloor\frac{n}{3} \mid\right)-1\right.}^{\prime}, v_{3\left\lfloor\frac{n}{3}\right]}^{\prime}\right\} U \\
& \left\{v_{(n-1)-1}, v_{(n-1)+1}, v_{(n-1)-1}^{\prime}, v_{(n-1)+1}^{\prime}, u_{(n-1)-1}, u_{n-1}, u_{(n-1)-1}^{\prime}, u_{n-1}^{\prime}\right\}=V \text {. }
\end{aligned}
$$

Sehingga diperoleh bilangan dominasi total $\gamma_{t}\left(S^{\prime}\left(T_{n}\right)\right) \leq\left\lfloor\frac{2 n}{3}\right\rfloor$. Selanjutnya, akan ditunjukkan bilangan dominasi total minimum pada splitting graph $\gamma_{t}\left(S^{\prime}\left(T_{n}\right)\right)=\left\lfloor\frac{2 n}{3}\right\rfloor$. Misalkan, $\gamma_{t}\left(S^{\prime}\left(T_{n}\right)\right)=$ $\left\lfloor\frac{2 n}{3}\right\rfloor-1$ maka terdapat $\left\lfloor\frac{2 n}{3}\right\rfloor-1$ titik yang merupakan kardinalitas minimum dari himpunan dominasi total splitting graph pada triangular snake graph. Jika terdapat $\left\lfloor\frac{2 n}{3}\right\rfloor-1$ titik pada himpunan dominasi total yang dipilih sembarang maka mengakibatkan terdapat paling minimum 1 titik dan maksimum 4 titik pada graf $S^{\prime}\left(T_{n}\right)$ yang tidak terdominasi. Jadi, dapat disimpulkan bilangan dominasi total splitting graph pada triangular snake graph yaitu $\gamma_{t}\left(S^{\prime}\left(T_{n}\right)\right)=\left\lfloor\frac{2 n}{3}\right\rfloor$. 


\section{KESIMPULAN}

Himpunan $S \subseteq V$ adalah himpunan dominasi total dalam $G$ jika $N(S)=V$. Bilangan dominasi total pada triangular snake graph, line graph dan splitting graph dapat diperoleh dengan cara mencari satu persatu himpunan dominasi total dari masing-masing graf dengan syarat bahwa setiap $N(S)=V$ sehingga diperoleh pola bilangan dominasi total pada masing-masing graf. Pada penelitian ini diperoleh bilangan dominasi total dari beberapa graf yaitu $\gamma_{t}\left(T_{n}\right)=\left\lfloor\frac{2 n}{3}\right\rfloor, \gamma_{t}\left(L\left(T_{n}\right)\right)=\left\lceil\frac{2 n}{3}\right\rceil$, $\gamma_{t}\left(S^{\prime}\left(T_{n}\right)\right)=\left\lfloor\frac{2 n}{3}\right\rfloor$.

\section{DAFTAR PUSTAKA}

[1] Henning MA dan Yeo A. Total Domination in Graphs. New York: Springer Science Business Media; 2013.

[2] Harris JM, Hirst LJ dan Mossinghoff JM. Combinatorics and Graph Theory. New York: Springer Science Business Media; 2008.

[3] Hernando C, Mora M dan Pelayo M. Locating Domination in Bipartite Graphs and Their Complements. Universitat Politecnica de Catalunya. 2017.

[4] Munir R. Matematika Diskrit, Ed ke-3. Bandung: Informatika; 2010.

[5] Santoso B, Djuwandi dan Soelistyo RH. Bilangan Dominasi dan Bilangan Kebebasan Graf Bipartit Kubik. Jurnal Matematika. 2012; Vol. 15.

[6] Wardani DAR, Agustin IH dan Dafik. Bilangan Dominasi dari Graf-Graf Khusus. Journal Proceeding. 2014; Vol. 1.

[7] Atapour M dan Soltankhah N. On Total Domination Sets in Graphs. Int J Contemp Math Sciences. 2009; Vol. 4.

[8] Lissie AJ dan Jaya S. Triple Connected Domination Number For Some Special Graphs. International Journal of Current Research and Modern Education. 2017.

[9] Roza I, Narwen dan Zulakmal. Graf Garis (Line Graph) dari Graf Siklus, Graf Lengkap dan Graf Bintang, Jurnal Matematika UNAND. 2014; Vol. 3.

[10] Ghosh P, Mishra SN dan Pal A. Various Labeling on Bull Graph and some Related Graphs. International Journal of Applications of Fuzzy Sets and Artificial Intelligence. 2015; Vol. 5.

MURTI

MARIATUL KIFTIAH

FRANSISKUS FRAN
: Jurusan Matematika FMIPA UNTAN, Pontianak murti27@student.untan.ac.id

: Jurusan Matematika FMIPA UNTAN, Pontianak kiftiahmariatul@math.untan.ac.id

: Jurusan Matematika FMIPA UNTAN, Pontianak fransiskusfran@math.untan.ac.id 